\title{
RNA Interference and Heterochromatin Assembly
}

\author{
Tom Volpe ${ }^{1}$ and Robert A. Martienssen ${ }^{2}$ \\ ${ }^{1}$ Department of Molecular and Cellular Biology, Northwestern University, Chicago, Illinois 60611 \\ ${ }^{2}$ Cold Spring Harbor Laboratory, Cold Spring Harbor, New York 11724 \\ Correspondence: martiens@cshl.edu
}

\section{SUMMARY}

In most eukaryotes, histone and DNA modifications are responsible for the silencing of genes integrated in heterochromatic sequences, as well as the silencing of pericentromeric repeats and transposable elements themselves. But the mechanisms that guide these modifications to heterochromatin during the cell cycle have been elusive. RNA interference takes advantage of heterochromatic transcription to process small RNAs and recruit enzymes required for both histone and DNA modifications, and is one such mechanism that has been identified. The processes are best understood in fission yeast and plants, but recent work in mammalian cells, especially in the germline, suggests these mechanisms may be highly conserved.

\section{Outline}

1 Introduction

2 Heterochromatin and heterochromatic modifications

3 RNA interference

4 Heterochromatic RNA interference at fission yeast centromeres
5 Heterochromatic silencing on chromosome arms

6 RNAi-dependent heterochromatic silencing in other eukaryotes

7 Conclusions

References

Editors: John F. Atkins, Raymond F. Gesteland, and Thomas R. Cech

Additional Perspectives on RNA Worlds available at www.cshperspectives.org

Copyright (C 2011 Cold Spring Harbor Laboratory Press; all rights reserved; doi: 10.1101/cshperspect.a003731

Cite as Cold Spring Harb Perspect Biol 2011;3:a003731 


\section{INTRODUCTION}

Heterochromatin is defined as chromosomal material that remains condensed during interphase, when euchromatin unravels co-incident with gene expression. Heterochromatin is faithfully inherited from one cell cycle to the next, but (at least in some cases) can be reset in each sexual generation, and so fulfills many of the criteria for epigenetic inheritance (Djupedal and Ekwall 2009). Nonetheless the function of heterochromatin is still incompletely understood. One important function is the ability to silence genes that are closely linked to heterochromatin-leading to the concept of "spreading" of silencing from one chromosomal location to the next. This type of heterochromatic silencing is known as "position effect variegation" (PEV) (Fig. 1), in which variegation refers to the mosaic pattern of silencing visualized by clones of cells in the developing eye of Drosophila (Huisinga and Elgin 2009). Since its discovery in the 1930s, more than 100 loci have been identified that either enhance or suppress PEV, which is also acutely sensitive to the position of the gene on a chromosome, to dosage, and to environmental factors such as temperature and nutrition (Ebert et al. 2006).

Importantly, silencing of transposons shares many of the same properties as PEV, and was recognized as a related phenomenon when it was first discovered in maize in the 1950s (Lippman and Martienssen 2004). Since the advent of genome sequencing, it is clear that transposons make up a substantial portion of heterochromatic sequences in most eukaryotes, and heterochromatic silencing has become a paradigm for epigenetic mechanisms of gene

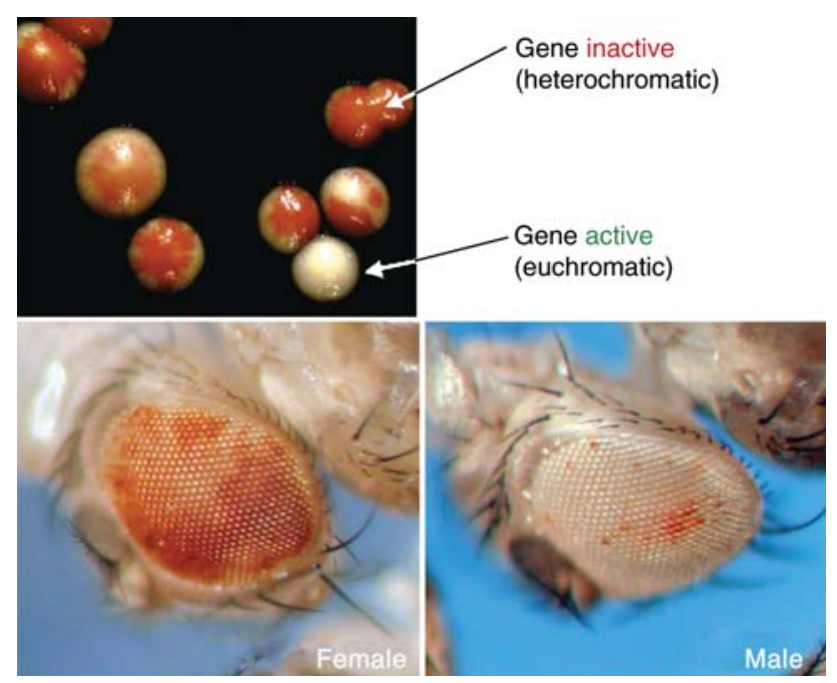

Figure 1. Position effect variegation in Drosophila and fission yeast. In Drosophila, the white gene $w[m 4 h]$ is silenced by heterochromatin, causing white sectors on an otherwise red eye. Silencing is enhanced in males. In fission yeast, loss of ade6 silencing when integrated near heterochromatic sequences gives rise to white sectors on red colonies. regulation. However, although silencing clearly has a role in regulating transposable elements, the biological function of PEV remains unclear. In addition to its role in silencing, heterochromatin also has profound effects on chromosome organization, especially at centromeres in which it plays a major role in establishing the kinetochore (Durand-Dubief and Ekwall 2008).

RNA is an attractive intermediate in heterochromatic silencing and spreading, as base-pairing with target sequences might account for sequence specificity. Furthermore, RNA interference has been established as a potent silencing mechanism, albeit at the posttranscriptional level. Silencing is accomplished by the Argonaute family of RNase H-related endonucleases, which use 20-30nt small RNA to guide cleavage or translational inhibition of target mRNA (see Joshua-Tor and Hannon 2010). In this article we review the role of RNA interference in establishment and maintenance of heterochromatic transcriptional silencing, focusing on studies in the fission yeast Schizosaccharomyces pombe.

\section{HETEROCHROMATIN AND HETEROCHROMATIC MODIFICATIONS}

Heterochromatin is distinguished by the covalent modification of histones and of DNA. Histone modifications specific to heterochromatin are more highly conserved and are found in organisms that lack DNA methylation, such as fission yeast and Caenorhabditis elegans, as well as in most animals and plants, in which DNA methylation is widespread. 5-methyl cytosine at symmetric CpG dinucleotides, on the other hand, is found in all plant and vertebrate genomes, but is lacking from some invertebrate and fungal genomes (Feng et al. 2010). CpG methylation is maintained by the methyltransferase Dnmt1, and guided during DNA replication by the hemimethylation binding protein Uhfr1, and their orthologs MET1 and VIM1 in plants, respectively. In plants and filamentous fungi heterochromatic sequences are also enriched in $\mathrm{CpNpG}$ as well as asymmetric $(\mathrm{CpHpH})$ methylation, which are targeted by alternative DNA methyltransferases (Henderson and Jacobsen 2007). However, DNA methylation in these contexts is much rarer in animal genomes, in which CG methylation is distributed more widely (Popp et al. 2010).

Histone modifications include methylation of histone H3 lysine-9 (H3K9), methylation of H3K27 (in multicellular animals and plants) and $\mathrm{H} 3$ arginine-2, as well as demethylation of H3K4, deubiquitination of $\mathrm{H} 2 \mathrm{BK} 123$ and deacetylation of several lysine residues in histones $\mathrm{H} 3$ and H4 (Garcia et al. 2007). Importantly, these modifications occur in readily accessible, unstructured histone "tails" that extrude from the nucleosome, and enzymes such as SET domain methyltransferases can modify nucleosomes 
in situ, without having to (completely) unravel individual nucleosomes. Additional covalent modifications are found in internal domains, which presumably can only be efficiently targeted to histone monomers and dimers. Methylation of lysine residues by SET domain methyltransferases can result in mono- (me1), di- (me2), or tri- (me3) methylated derivatives, and different derivatives are associated with heterochromatin in different species. Demethylation is accomplished sequentially by Jumonji C (JmJC)-domain oxidoreductases (from me3 to me2 to me1) and Lysine Specific Demethylase (LSD)-like amine oxidases (from me2 to me1) (Mosammaparast and Shi 2010). Deacetylation is accomplished by type I and type II deacetylases as well as type III, or "sirtuin" deacetylases that use an NADH cofactor(Shahbazian and Grunstein 2007). Importantly, many of these enzymes can also modify nonhistone proteins, such as the DNA methyltransferase Dnmt1, and so impact chromatin modification indirectly as well (Nicholson and Chen 2009).

Modifications of histone tails are specifically recognized by "effector" and "adaptor" proteins that recognize intact modified nucleosomes (Taverna et al. 2007). Adaptor domains include chromodomains, PHD domains, and WD repeat domains (all of which bind methylated lysines), bromodomains and BAH domains (which bind acetylated lysines) and 14-3-3 domains (which bind phosphorylated serines). Recognition can be reduced by nearby modifications, such as S10 phosphorylation (which prevents K9me2/3 recognition by chromodomains) or R2 methylation (which prevents K4me3 recognition by PHD domains), or enhanced by modification of other histone tails or even of the underlying DNA sequence itself (Cheng and Blumenthal 2010). Effector domains include a variety of enzymatic activities such as ATP-dependent chromatin remodeling and further histone and DNA modification. These observations have led to the idea that a combination (or code) of chromatin modifications is required to dictate any given readout (Jenuwein and Allis 2001).

Many of the enzymes that modify histones, as well as proteins that recognize them, were first discovered in genetic screens for mutants that either enhance or suppress position effect variegation in Drosophila, and related silencing phenomena in yeast, other animals and plants. For example SuVar (suppressor of variegation) 3-9, responsible for H3K9 methylation, was first discovered in Drosophila, but homologs were subsequently found in almost every other eukaryotic genome (Ebert et al. 2006).

\section{RNA INTERFERENCE}

Double-stranded RNA (dsRNA) can trigger posttranscriptional silencing of cognate genes through sequence specific recognition of endogenous transcripts (see Joshua-Tor and Hannon 2010). The RNase III enzyme, Dicer, specifically cleaves dsRNA into small interfering RNAs (siRNA) 21$24 \mathrm{nt}$ in length. These siRNAs can act as guides to target effector complexes, such as the RNA-induced silencing complex (RISC), to endogenous transcripts in a sequencespecific manner resulting in cleavage and subsequent degradation or in translational inhibition. Several components of RISC have been isolated. One of these components, the small RNA binding protein Argonaute, is a key effector and can cleave endogenous messages via its endonuclease domain, which resembles RNaseH. RNA dependent RNA polymerase (RdRP) is thought to be involved in amplification of small interfering RNAs (siRNAs) in some organisms by using endogenous messages as templates to generate additional dsRNA substrates.

RNAi is found in almost all eukaryotes though interesting exceptions exist. The budding yeast $S$. cerevisiae appears to have lost the RNAi machinery (Aravind et al. 2000), although recent studies of other budding yeast species reveal the presence of Argonaute as well as noncanonical Dicer genes and suggest their involvement in transposon regulation (Drinnenberg et al. 2009). Similarly, whereas the function of RdRP has been well studied in plants, worms, and fission yeast, RdRP genes in insects and mammals have been elusive. Recent studies, however, had revealed RdRP activity in Drosophila and in humans suggesting that the activity itself is conserved (Lipardi and Paterson 2009; Maida et al. 2009).

Many RNAi mechanisms depend on dsRNA, and aside from exogenous sources (such as viruses and transgenes), dsRNA can also be generated endogenously. One mechanism involves bidirectional transcription followed by annealing of complementary transcripts, although the large amount of antisense transcription observed in eukaryotic genomes raises questions regarding specificity. Another method involves dsRNA synthesis via RdRP activity on single stranded RNA templates. Exogenously generated siRNA, or "primary siRNAs" directing amplification of endogenous "secondary siRNAs" via activity of RdRP has been shown in plants and worms, and occurs in fission yeast (Halic and Moazed 2010).

In higher eukaryotes endogenously expressed single stranded stem-loop RNAs are recognized and processed by Dicer resulting in small RNA molecules known as micro RNAs (miRNAs). miRNAs are incorporated into Argonaute, which then targets RISC to endogenous transcripts. This targeting results in posttranscriptional silencing via inhibition of translation or, in some cases, cleavage of the associated message (Aravin and Hannon 2008). The versatility of miRNAs in regulation of gene expression is vast, and some miRNAs have also been shown to result in 
transcriptional activation as well as repression (Kim et al. 2008). Yet another class of small RNAs, PIWI interacting RNAs (piRNAs), require neither Dicer nor RdRP for biogenesis and associate with a subset of argonaute homologs called PIWI proteins. These piRNAs have been implicated in germ line development, transposon regulation, and genome organization (Thomson and Lin 2009). The biogenesis and function of miRNA and piRNA are described by Joshua-Tor and Hannon (2010).

\section{HETEROCHROMATIC RNA INTERFERENCE AT FISSION YEAST CENTROMERES}

S. pombe has proven to be a powerful system for studying the endogenous function of RNAi. One reason is that the fission yeast genome contains only a single homolog each of Dicer, Argonaute, and RdRP thus eliminating much of the redundancy exhibited in other organisms (Aravind et al. 2000; Carmell et al. 2002). One startling discovery from early studies in fission yeast was the dramatic loss of reporter gene silencing near centromeres in the absence of RNAi, which was accompanied by the accumulation of transcripts derived from heterochromatic repeats (Volpe et al. 2002). These observations suggested that heterochromatic silencing was mediated, at least in part, by RNA interference.

Heterochromatin in $S$. pombe exists at centromeres, telomeres, and the silent mating-type locus (Cam et al. 2005). Proper heterochromatin assembly at centromeres and telomeres is required for chromosome stability whereas heterochromatin within regions of the mating-type locus is required for proper cell fate determination. A major function of heterochromatin at centromeres appears to be the recruitment of cohesin, which is required for proper chromosome segregation. This recruitment is mediated by the $S$. pombe HP1 homolog Swi6, which can bind both H3K9me2 and cohesin (Bernard et al. 2001). The centromeres of the three fission yeast chromosomes (Fig. 2) are organized in a similar manner in that each is composed of a central core region (cnt) enriched with the histone variant Cenp-A and the site of kinetochore assembly (DurandDubief and Ekwall 2008). The central core is then flanked by large inverted repeats referred to as the innermost repeats (imr). The central and innermost regions are further flanked by tandem alternating copies of $\mathrm{dg}$ and dh centromeric repeats (Takahashi et al. 1991); it is from these the outermost repeats (otr) that most centromere transcription originates (Volpe et al. 2002).

Heterochromatic RNAs are expressed bidirectionally from both the top (forward transcripts) and the bottom (reverse transcripts) DNA strands in $r d p 1^{-}$(RNA-dependent RNA polymerase), dcr1 ${ }^{-}$(Dicer), and agol- (Argonaute) mutant cells. Analysis of nascent RNA by nuclear run-on revealed reverse strand centromeric transcripts are synthesized but rapidly degraded in both wild type and swi6 ${ }^{-}$mutant cells, suggesting that RNAi is involved in the posttranscriptional degradation of reverse strand centromeric transcripts. In addition, nascent forward strand transcripts were not detected by nuclear run-on in wild type. These transcripts do accumulate in swi6 ${ }^{-}$mutants, however, suggesting the promoter driving forward transcription is transcriptionally silenced in wild type cells and this silencing is dependent on Swi6. Furthermore, accumulation of forward strand centromeric transcripts

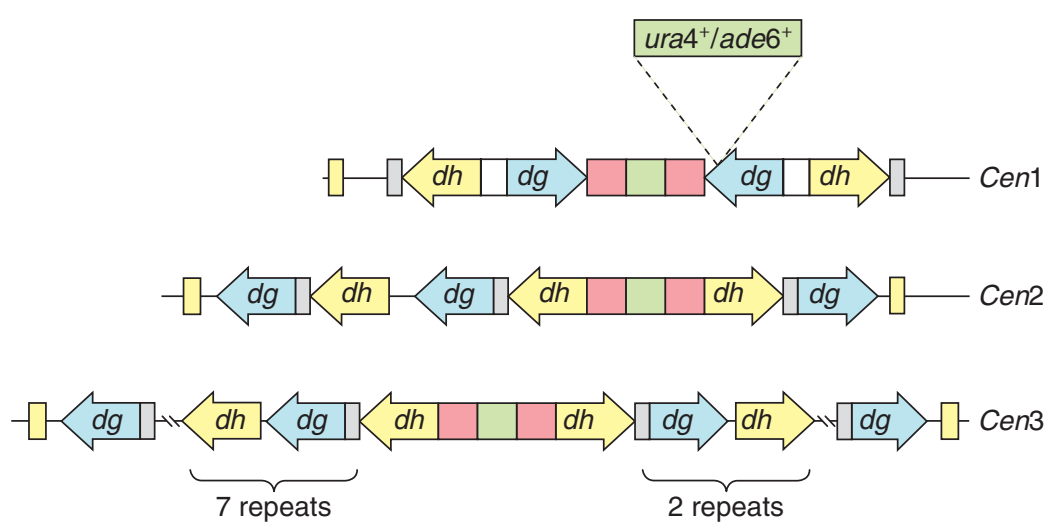

Figure 2. Centromeric heterochromatin in the fission yeast S. pombe. The three centromeres of S. pombe each include a central region (green rectangles) flanked by large inverted innermost repeats (red rectangles). These are flanked by tandem copies of outermost elements (blue arrows, orange arrows, white rectangles and grey rectangles) that are composed of dg and dh repeats. Centromeres also contain clusters of tRNA genes (yellow rectangles) at the boundaries between heterochromatin and euchromatin. Reporter genes integrated into centromere 1 (ade6 or ura4) are silenced by RNAi-mediated heterochromatic silencing. 
in RNAi mutants suggests transcriptional regulation of the forward promoter is also regulated by RNAi (Volpe et al. 2002). Therefore, both transcriptional and posttranscriptional mechanisms are involved in silencing of centromeric repeats in $S$. pombe.

Heterochromatic regions such as the $S$. pombe centromeric repeats are normally enriched in the chromodomaincontaining Swi6 protein and H3K9me2 whereas sites of active transcription are associated with $\mathrm{H} 3 \mathrm{~K} 4 \mathrm{me} 2$ (Cam et al. 2005). However, in RNAi mutants Swi6 and H3K9me2 enrichment is replaced by $\mathrm{H} 3 \mathrm{~K} 4 \mathrm{me} 2$ (Volpe et al. 2002). This led to a model in which transcripts derived from heterochromatic centromeric repeat sequences are processed by the RNAi machinery resulting in sequence specific targeting of histone modifications to centromeres. This was further supported by the identification of small interfering RNAs (siRNAs) corresponding to $S$. pombe centromeric transcripts and the discovery that at least one component of the RNAi machinery, RdRP, is enriched at centromeric repeat sequences (Reinhart and Bartel 2002; Volpe et al. 2002). Insights into effector complexes involved in RNAi mediated heterochromatin assembly mechanisms would soon follow (summarized in Fig. 3).

Biochemical purification of the fission yeast chromodomain-containing protein, Chp1, identified an RNAi effector complex consisting of Chp1, Ago1, and a novel protein, Tas3 as well as heterochromatic siRNAs (Verdel et al. 2004). This complex, the RNA-induced initiation of transcriptional silencing complex (RITS), is associated with heterochromatin (Verdel et al. 2004; Cam et al. 2005). This enrichment appears to be mediated by base pairing of RITS associated siRNAs with heterochromatic nascent transcripts, although it has also been shown that binding of RITS to heterochromatic regions requires H3K9me2, which is recognized by the Chp1 chromodomain (Schalch et al. 2009). RITS can then recruit several other protein complexes to heterochromatin.

One protein complex recruited by RITS is the RNA-directed RNA polymerase complex (RDRC), which consists of Rdp1, the RNA helicase Hrr1, and the oligoadenylate polymerase Cid12. This complex acts on singlestranded RNA templates to generate dsRNA independently of siRNA primers (Motamedi et al. 2004). RITS association with RDRC is dependent on heterochromatin as well as siRNAs (Motamedi et al. 2004). The endonuclease activity of Ago 1 is used first in a siRNA processing step whereby one strand of the siRNA duplex is "sliced" to yield single stranded siRNA. This siRNA processing step occurs in a complex called ARC, which acts to chaperone siRNA duplexes generated by Dicer to the RITS complex (Buker et al. 2007). Once in the RITS complex, the slicer activity of Agol on heterochromatin transcripts has a further function in generating $3^{\prime}$ ends to act as substrates for RdRP (Irvine et al. 2006; Halic and Moazed 2010).

But most importantly, the catalytic activity of RITS is required for recruitment and spreading of a multifunctional histone modification complex known as the CLRC complex (Irvine et al. 2006). Along with the WD repeat protein Rik1, which resembles DDB1 (DNA damage binding protein), CLRC contains the sole $S$. pombe lysine 9 histone methyltransferase $\mathrm{Clr} 4$, as well as the $\mathrm{H} 3 \mathrm{~K} 4$ demethylase Lid2 and the cullin4 ubiquitin E3 ligase, and two other

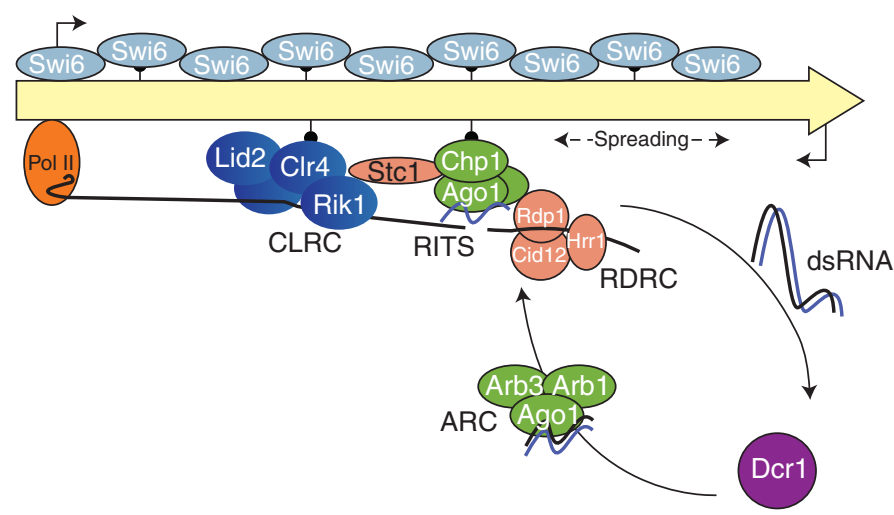

Figure 3. Model for heterochromatin assembly and spreading at $S$. pombe centromeric outer repeats. Heterochromatic centromere sequences (yellow arrow) are transcribed by RNA Polymerase II. These centromere transcripts are targeted by RITS via siRNA loaded Agol. Association of RITS with centromere heterochromatin is strengthened by binding of Chp1 to H3mK9. RITS activity can recruit both CLRC, via interactions with Stc1, and RDRC resulting in spreading of $\mathrm{H} 3 \mathrm{mK} 9$ and amplification of siRNAs, respectively (see text for details). dsRNA generated either by bi-directional transcription from centromere promoters (black arrows) or by RDRC activity is recognized and processed by Dicer (Dcr1). The resulting centromere siRNAs are then loaded onto Agol first in the ARC complex and then in RITS. 
proteins, Clr7 and Clr8 (Horn et al. 2005; Jia et al. 2005; Li et al. 2005; Li et al. 2008). Therefore, RITS association with heterochromatin acts both to amplify siRNAs and also to modify nucleosomal histones and thus reinforce heterochromatin in a sequence specific manner (Fig. 3). The bridging protein that allows interaction between RITS and CLRC has been identified as the LIM domain protein Stc1, which can interact with both Agol and Clr4 (Bayne et al. 2010). Further, Clr4 has the ability to bind H3K9me2 via its chromodomain(Zhang et al. 2008). This suggests a mechanism of heterochromatin spreading whereby recruitment of $\mathrm{Clr} 4$ by H3K9me2 allows modification of adjacent nucleosomes.

A key element in the formation of heterochromatic siRNAs, and therefore heterochromatin assembly, is the regulation of transcription within these domains. It seems paradoxical that transcription of heterochromatin triggers transcriptional silencing of these very same sequences. Insight into this paradox was provided by the finding that centromeric transcription is regulated in a cell cycle dependent manner (Kloc et al. 2008). Centromere repeat transcription is limited to the G1 and S phase of the cell cycle coinciding with increases in Pol II occupancy at centromeres (Chen et al. 2008). This is the time when
H3K9me2 is at its lowest, and Swi6 occupancy is reduced because of phosphorylation of H3S10, which prevents chromodomain binding (Fig. 4). Repeat transcription in early S-phase is followed by increases in siRNAs and in H3K9me2 that peaks in G2 (Kloc et al. 2008). Thus, centromere repeat expression in early S-phase occurs when pericentromeric heterochromatin is replicated and could provide a timely means for inheritance of the silent state by newly replicated chromatin (Fig. 4).

Mutations in RNA Polymerase II subunits have effects on centromere silencing, indicating that heterochromatin transcripts are Pol II derived (Djupedal et al. 2005) and that pol II plays an important role in the silencing process. For example, viable mutants in Rpb7 prevent accumulation of centromeric reverse transcripts and siRNA, whereas mutants in Rpb2 lose siRNA, but not centromere transcription, indicating that Pol II participates in both precursor (pre-siRNA) transcription and processing (Kato et al. 2005). As might be expected, factors involved in RNA processing also play a role in centromeric silencing. Mutants in several RNA splicing factors, including $\operatorname{prp5}$, $\operatorname{prp} 8$, and prp10 have strong defects in siRNA accumulation and centromeric reporter gene silencing (Bayne et al. 2010). Mutations in the exosome exonucleases Dis3 and Rrp6 also affect

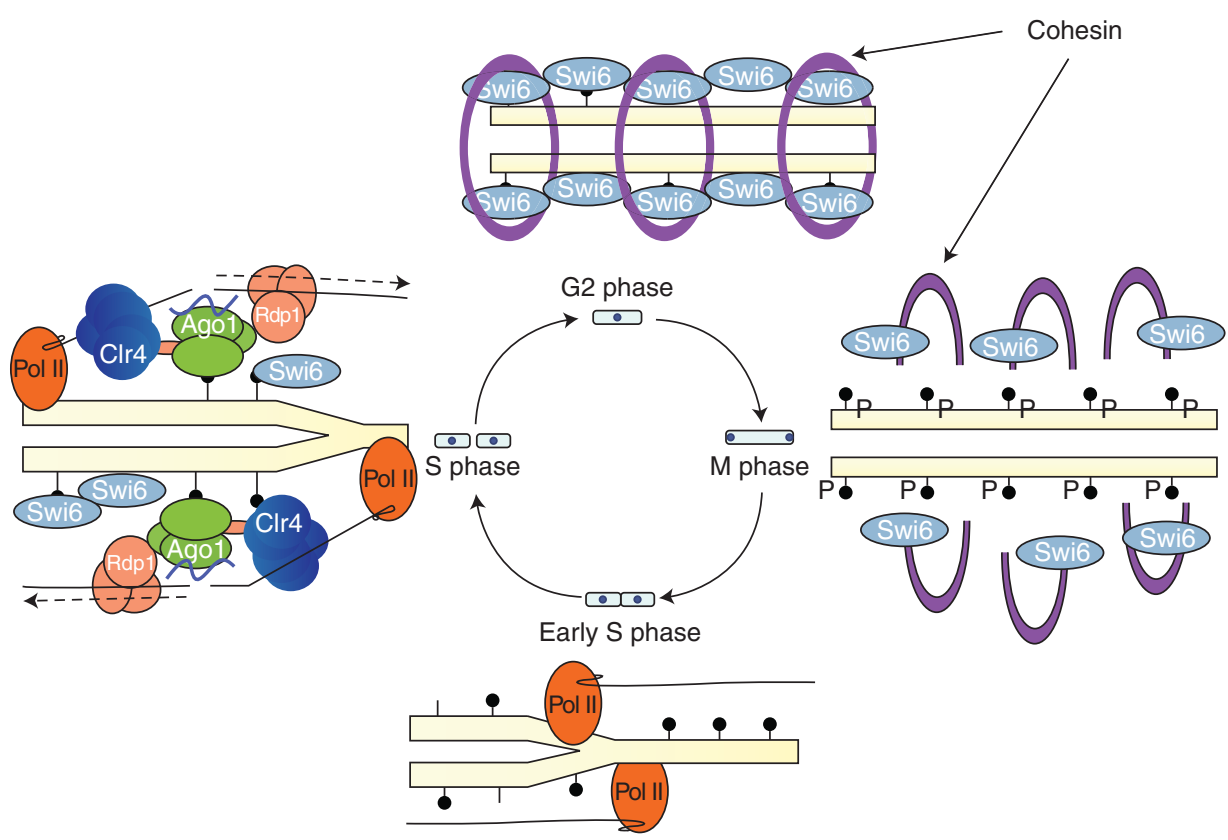

Figure 4. Cell cycle regulation of heterochromatin transcription and assembly. Pericentromeric heterochromatin is silent through most of the cell cycle (G2) but is transcriptionally activated when Swi6 (the HP-1 homolog) is evicted from methylated histone $\mathrm{H} 3$ lysine- 9 by phosphorylation of histone $\mathrm{H} 3$ serine-10. Transcription continues during G1 and S phase, when transcripts are processed by RNAi and converted into siRNA. Replication during early S phase replaces approximately half of the parental nucleosomes with freshly assembled nucleosomes that lack $\mathrm{H} 3 \mathrm{~K} 9 \mathrm{me} 2$. The RITS complex promotes H3K9 methylation and H3K4 demethylation, by the CLRC complex, which recruits Swi6 and silences heterochromatin in the subsequent G2. Thus transient expression and siRNA production during $S$ phase promotes epigenetic inheritance of heterochromatic modifications. 
reporter gene silencing whereas mutants in the TRAMP complex oligoadenylate polymerase Cid14 prevent siRNA accumulation as well (Murakami et al. 2007; Buhler et al. 2008). Most of these mutations, however, have a much lower impact on centromere transcript accumulation and/or heterochromatin assembly relative to RNAi. One possibility is that these effects are mostly posttranscriptional and that transcriptional silencing remains largely intact. For example, pre-siRNA transcripts that are cleaved by Argonaute are stabilized in cells deficient for Rrp6 (Irvine et al. 2006).

RNAi is not the only mechanism that guides histone modification to the centromeric repeats. The histone deacetylase Clr3 is partially redundant with RNA interference, so that double mutants lose $\mathrm{H} 3 \mathrm{~K} 9 \mathrm{me} 2$ completely, whereas single RNAi mutants lose H3K9me2 predominantly from embedded reporter genes but retain residual levels over centromeric repeats. In clr3 mutants, the levels of siRNA actually increase, indicating enhanced silencing at the post-transcriptional level (Yamada et al. 2005).

\section{HETEROCHROMATIC SILENCING ON CHROMOSOME ARMS}

Unlike at centromeres, heterochromatin contained within the silent mating type-locus and sub-telomeric regions is maintained in $r d p 1^{-}, d c r 1^{-}$and ago1 $1^{-}$mutants. Heterochromatin initiation at the mating type locus, however, seems to require RNAi (Hall et al. 2002). Once established, heterochromatin maintenance at the silent mating-type locus is dependent on the stress activated ATF/CREB (activating transcription factor/cAmp response-element binding protein) family members Atf1 and Pcr1 which can recruit Swi6 protein independently of RNAi (Jia et al. 2004). Interestingly, RNAi dependent heterochromatin assembly also occurs at sites of convergent gene transcription resulting in transient recruitment of Swi6 and binding of cohesin along chromosome arms (Gullerova and Proudfoot 2008).

Proper targeting of heterochromatin is extremely important, because misregulation of assembly can lead either to the expression or silencing of the wrong genes. Interestingly, some portions of centromeric repeat sequences integrated within euchromatic sequences are sufficient to recruit heterochromatin assembly resulting in silencing of adjacent reporter genes suggesting that these sequences act as heterochromatin nucleation elements (Ayoub et al. 2000; Partridge et al. 2002). This ectopic silencing requires factors involved in heterochromatin assembly at endogenous centromeres including RNAi (Hall et al. 2002; Volpe et al. 2003).

Whether regions of centromere homology normally nucleate heterochromatin formation in cis or in trans is not clear. Early studies of the effects of hairpin derived siRNAs in S. pombe suggested that only posttranscriptional silencing of target mRNAs occurs with no obvious transcriptional silencing effects found in other organisms (Mette et al. 2000; Morris et al. 2004; Sigova et al. 2004). Further studies addressed cis versus trans silencing by tethering components of the RITS complex to RNA transcripts of a euchromatic $\mathrm{ura}^{+}{ }^{+}$reporter gene. Interestingly, this resulted in heterochromatin assembly at the euchromatic ura $4^{+}$locus. In addition, siRNAs corresponding to ura 4 sequences were observed in these strains suggesting that ura4 transcripts were being processed by RNAi (Buhler et al. 2006). These studies also addressed whether ura 4 siRNAs were capable of targeting heterochromatin assembly to a second ura4 reporter in trans. In a wild-type background no trans targeting was observed suggesting that the ura4 siRNAs could only silence in cis. However, in certain strain backgrounds, such as an eril mutant, heterochromatin appeared to be assembled in trans albeit inefficiently (Buhler et al. 2006).

Eri1 is an RNA nuclease that was first identified in C. elegans in a screen for mutants that enhanced RNA interference on injection of exogenous siRNAs. Mutations in Eri-1 resulted in a more robust silencing of the reporter suggesting that it acts as an inhibitor of RNAi (Kennedy et al. 2004). Consistent with this early report, Eril appears to play a negative role in the assembly of heterochromatin in S. pombe (Iida et al. 2006). Another study suggests, however, that although $C$. elegans Eri-1 may interfere with effects from exogenous siRNAs, it is actually required for post-transcriptional gene silencing triggered by endogenously expressed siRNAs (Duchaine et al. 2006). Therefore Eril could have a role in promoting as well as inhibiting heterochromatin assembly.

Results from two recent studies indicate trans-targeting can in fact occur under some circumstances in fission yeast. First, it was found that siRNAs corresponding to reporter gene sequences resulted in heterochromatin targeting to a euchromatic site (Simmer et al. 2010). Interestingly, this trans targeting appears to be dependent on the location of the euchromatic target being near established heterochromatin. Second, Dcr1 protein is found in intracellular foci that are distinct from those containing centromere chromatin (Emmerth et al. 2010). This suggests that processing of centromere siRNAs does not occur at the site of transcription. Trans targeting of heterochromatin assembly has been observed in other systems (Mette et al. 2000; Morris et al. 2004) and in fission yeast portions of both the silent mating-type locus and telomeres contain regions of centromere homology (Grewal and Klar 1997; Mandell et al. 2005) suggesting these sequences can act as trans targets for signals such as siRNAs. Importantly, these regions 
of centromere homology coincide with the centromeric regions known to be expressed and have been shown to function as heterochromatin nucleation elements suggesting that heterochromatin formation within these regions is mediated by a common mechanism (Volpe et al. 2003).

\section{RNAi-DEPENDENT HETEROCHROMATIC SILENCING IN OTHER EUKARYOTES}

Although the mechanisms of RNAi mediated heterochromatin assembly discovered in S. pombe are highly conserved, their role in higher eukaryotes is still being explored. In part this is because other transcriptional silencing mechanisms, most importantly DNA methylation, are found in mammals as well as in plants and filamentous fungi (such as Neurospora crassa). Furthermore. RNAi in animals appears to operate largely in the germline, rather than in cell lines and primary cells in which its impact on heterochromatin would be easier to measure. The extent to which DNA methylation in the mammalian germline is influenced by RNAi is discussed in the article by Joshua-Tor and Hannon (2010). Recently, a similar prominence for RNAi in germline silencing has been discovered in plants, and indeed it is in plants that the role of RNA in gene silencing was first described and is arguably the best understood.

When cDNA copies of plant RNA viruses are artificially integrated into the genome as transgenes, they are susceptible to DNA methylation, which is promoted by subsequent infection with viral RNA (Wassenegger et al. 1994). Viral infection can also lead to posttranscriptional silencing, if copies of chromosomal genes are included in the infectious viral genome (Ruiz et al. 1998). Similarly, when plant transgenes are integrated in the genome, they are often methylated by mechanisms that depend on RNAi especially when they carry sequences that match transposon small RNA (Chan et al. 2006).

The genes required for both posttranscriptional and transcriptional silencing have been painstakingly isolated in genetic screens, and have led to a comprehensive picture of the mechanism by which small RNA leads to transcriptional gene silencing in plants (Vaucheret et al. 2001; Baulcombe 2004; Bender 2004; Henderson and Jacobsen 2007; Matzke et al. 2009). Silent transgenes, and many transposable elements, are transcribed by a plant-specific RNA polymerase related to Pol II, known as Pol V (Wierzbicki et al. 2009). Silencing is promoted by a factor related to SPT5, first described as a protein required for transposon transcription in yeast (He et al. 2009), as well as a chromatin remodeling enzyme (DRD1) and an SMC hinge domain protein (Matzke et al. 2009). These transcripts interact with one of the ten Argonaute proteins found in plants, namely Ago4. Usually (though not always) this interaction depends on cleavage or "slicing" of the target transcripts (Qi et al. 2006). These transcripts are processed by a combination of RNA polymerases PolIV and RDR2 (an RdRP) into dsRNA intermediates that are substrates for one or more of the four classes of Dicer enzymes found in plants (Pikaard et al. 2008). The cycle is complete when dsRNA binding proteins such as SGS3 and its homologs bind and presumably unwind the dsRNA duplexes and load one strand onto Ago4 (Ausin et al. 2009).

As in S. pombe, the subsequent steps that connect RNA processing with transcriptional silencing in plants are still unclear. What is clear is that RNAi leads to histone modification, via Suvar 3-9 homologs including SUVH4/KYP, and to DNA methylation, via Dnmt3 homologs DRM1 and DRM2 and the chromomethylase CMT3. In each case, the enzymes responsible for one modification are guided by the other-for example, SUVH4/KYP has a methylcytosine-binding SRA domain with a preference for methylated $\mathrm{CpNpG}$ sites (the product of CMT3). On the other hand CMT3 has a chromodomain that binds H3K9me2, which is the product of SUVH4 (Johnson et al. 2007). The precise details of how the 3 CMT and 3 DRM methyltransferase homologs are recruited by RNAi are still being determined, but histone modifications and SUVH enzymes may play at least an intermediate role, reminiscent of the mechanism in fission yeast (Johnson et al. 2008).

Thus DNA and histone methylation are regulated via the 23-24nt siRNA pathway in plants. This pathway closely resembles the RNAi pathway in fission yeast, and as in S. pombe, RNAi-mediated heterochromatin formation is partially redundant with RNAi-independent mechanisms of heterochromatic modification, including (in plants) both histone deacetylation and DNA methylation (Lippman et al. 2003). The targets of heterochromatic modifications in plants include pericentromeric satellite sequences, as in fission yeast, but also many transposable elements (Hamilton et al. 2002; Lippman et al. 2003; May et al. 2005). As in S. pombe, RNAi can both establish as well as maintain heterochromatic modifications, unlike the methyltransferase MET1 and the chromatin remodeler DDM1, which can only maintain these modifications from one generation to the next (Teixeira et al. 2009).

In the pollen grain, down-regulation of the DDM1/ MET1 pathway leaves transposons uniquely sensitive to RNAi, giving rise to a new class of $21 \mathrm{nt}$ heterochromatic small RNA that are mobilized into the sperm cells (Slotkin et al. 2009). Transposons are similarly sensitive to RNAi in the egg cell, indicating a similar loss of RNAi-independent silencing on the female side (Olmedo-Monfil et al. 2010). It is thought that this prevalence of transposon small RNA in germ cells may contribute to interspecific "genome 
incompatibility" when they fail to recognize transposons from the other parent. Very importantly, mutants in RNAi on the male side result in meiotic failure and pollen inviability (Nonomura et al. 2007), whereas those on the female side result in misspecification of germ cells and the production of clonal, diploid eggs (Olmedo-Monfil et al. 2010). These mechanisms therefore have a profound role in plant reproduction.

In N. crassa, RNAi also plays a role in histone modification, gene silencing and in DNA methylation, although all three mechanisms do not always contribute to reporter gene silencing at the same time (Cogoni and Macino 1999; Tamaru and Selker 2001; Chicas et al. 2005). In meiosis, genes normally expressed at this time (such as spore color genes) are silenced if they are paired with a partially or completely deleted homolog (Kelly and Aramayo 2007). "Meiotic silencing of unpaired DNA," also occurs in worms, and also depends on RNAi, which is required to silence the unpaired $\mathrm{X}$ chromosome as well as transgene arrays in the germline (Kelly and Aramayo 2007). In both C. elegans and N. crassa $\mathrm{H} 3 \mathrm{~K} 9$ methylation and silencing depend on Argonaute and RdRP, although a role for Dicer has so far proved elusive (She et al. 2009), and the origin of siRNA precursor transcripts that are presumably involved remains a mystery. In perhaps the most dramatic example of RNAi-guided histone modification, RNAi and $\mathrm{H} 3 \mathrm{~K} 9 \mathrm{me} 2$ are required for elimination of intervening DNA and transposon related sequences in the protists Tetrahymena and Paramecium (Chalker 2005). Comparison of genome transcripts and small RNA via "scanning" is thought to result in modification and elimination of sequences from the new somatic macronucleus, guided by the germline micronucleus (Mochizuki et al. 2002). Clearly, RNAi-guided heterochromatin assembly has taken a prominent role in the germline of even the simplest eukaryotes.

\section{CONCLUSIONS}

The finding that RNA interference can guide epigenetic modification of histones and DNA raises important questions as to the origin and function of heterochromatin. Well known as a key factor in the organization of chromosomes, a developmental role for heterochromatin has been revealed by RNAi in the germlines of plants, protists, and animals. As a repository of transposon and other repeat sequences, heterochromatin is a source of sequence-specific epigenetic information-namely small RNA-that can silence transposons and modify chromosomes during meiosis and during mitosis, where small RNA provide a mechanism for epigenetic inheritance. Conversely, the programmed (or reprogrammed) loss of RNAi-mediated heterochromatin, for example during development, reproduction or senescence, has profound effects on cell fate, especially of germ cells and their descendents. The role of RNAi in heterochromatic modification may yet have more surprises in store.

\section{ACKNOWLEDGMENTS}

We thank Mikel Zaratiegui and Michele McDonough for helpful comments on the manuscript, Derek Goto and Jim Birchler for the images in Figure 1, and to our many colleagues and collaborators for their contributions to this field. Work in the authors' laboratories is funded by grants from the NIH R01-GM067014 (to RM) and R01GM074986 (to TV).

\section{REFERENCES}

Aravin AA, Hannon GJ. 2008. Small RNA silencing pathways in germ and stem cells. Cold Spring Harb Symp Quant Biol 73: 283-290.

Aravind L, Watanabe H, Lipman DJ, Koonin EV. 2000. Lineage-specific loss and divergence of functionally linked genes in eukaryotes. Proc Natl Acad Sci 97: 11319-11324.

Ausin I, Mockler TC, Chory J, Jacobsen SE. 2009. IDN1 and IDN2 are required for de novo DNA methylation in Arabidopsis thaliana. Nat Struct Mol Biol 16: 1325-1327.

Ayoub N, Goldshmidt I, Lyakhovetsky R, Cohen A. 2000. A fission yeast repression element cooperates with centromere-like sequences and defines a mat silent domain boundary. Genetics 156: 983-994.

Baulcombe D. 2004. RNA silencing in plants. Nature 431: 356-363.

Bayne EH, White SA, Kagansky A, Bijos DA, Sanchez-Pulido L, Hoe KL, Kim DU, Park HO, Ponting CP, Rappsilber J, et al. 2010. Stc1: A critical link between RNAi and chromatin modification required for heterochromatin integrity. Cell 140: 666-677.

Bender J. 2004. Chromatin-based silencing mechanisms. Curr Opin Plant Biol 7: 521-526.

Bernard P, Maure JF, Partridge JF, Genier S, Javerzat JP, Allshire RC. 2001. Requirement of heterochromatin for cohesion at centromeres. Science 294: 2539-2542.

Buhler M, Verdel A, Moazed D. 2006. Tethering RITS to a nascent transcript initiates RNAi- and heterochromatin-dependent gene silencing. Cell 125: 873-886.

Buhler M, Spies N, Bartel DP, Moazed D. 2008. TRAMP-mediated RNA surveillance prevents spurious entry of RNAs into the Schizosaccharomyces pombe siRNA pathway. Nat Struct Mol Biol 15: 1015-1023.

Buker SM, Iida T, Buhler M, Villen J, Gygi SP, Nakayama J, Moazed D. 2007. Two different Argonaute complexes are required for siRNA generation and heterochromatin assembly in fission yeast. Nat Struct Mol Biol 14: 200-207.

Cam HP, Sugiyama T, Chen ES, Chen X, FitzGerald PC, Grewal SI. 2005. Comprehensive analysis of heterochromatin- and RNAi-mediated epigenetic control of the fission yeast genome. Nat Genet 37: 809-819.

Carmell MA, Xuan Z, Zhang MQ, Hannon GJ. 2002. The Argonaute family: Tentacles that reach into RNAi, developmental control, stem cell maintenance, and tumorigenesis. Genes Dev 16: 2733-2742.

Chalker DL. 2005. Genome rearrangements: Mother knows best! Curr Biol 15: $827-829$.

Chan SW, Zhang X, Bernatavichute YV, Jacobsen SE. 2006. Two-step recruitment of RNA-directed DNA methylation to tandem repeats. PLoS Biol 4: e363. 
Chen ES, Zhang K, Nicolas E, Cam HP, Zofall M, Grewal SI. 2008. Cell cycle control of centromeric repeat transcription and heterochromatin assembly. Nature 451: 734-737.

Cheng X, Blumenthal RM. 2010. Coordinated chromatin control: Structural and functional linkage of DNA and histone methylation. Biochemistry 49: 2999-3008.

Chicas A, Forrest EC, Sepich S, Cogoni C, Macino G. 2005. Small interfering RNAs that trigger posttranscriptional gene silencing are not required for the histone $\mathrm{H} 3$ Lys9 methylation necessary for transgenic tandem repeat stabilization in Neurospora crassa. Mol Cell Biol 25: $3793-3801$.

Cogoni C, Macino G. 1999. Gene silencing in Neurospora crassa requires a protein homologous to RNA-dependent RNA polymerase. Nature 399: $166-169$.

Djupedal I, Ekwall K. 2009. Epigenetics: heterochromatin meets RNAi. Cell Res 19: 282-295.

Djupedal I, Portoso M, Spahr H, Bonilla C, Gustafsson CM, Allshire RC, Ekwall K. 2005. RNA Pol II subunit Rpb7 promotes centromeric transcription and RNAi-directed chromatin silencing. Genes Dev 19: 2301-2306.

Drinnenberg IA, Weinberg DE, Xie KT, Mower JP, Wolfe KH, Fink GR, Bartel DP. 2009. RNAi in budding yeast. Science 326: 544-550.

Duchaine TF, Wohlschlegel JA, Kennedy S, Bei Y, Conte D, Pang K, Brownell DR, Harding S, Mitani S, Ruvkun G et al. 2006. Functional proteomics reveals the biochemical niche of C. elegans DCR-1 in multiple small-RNA-mediated pathways. Cell 124: 343-354.

Durand-Dubief M, Ekwall K. 2008. Heterochromatin tells CENP-Awhere to go. Bioessays 30: 526-529.

Ebert A, Lein S, Schotta G, Reuter G. 2006. Histone modification and the control of heterochromatic gene silencing in Drosophila. Chromosome Res 14: 377-392.

Emmerth S, Schober H, Gaidatzis D, Roloff T, Jacobeit K, Buhler M. 2010. Nuclear retention of fission yeast dicer is a prerequisite for RNAi-mediated heterochromatin assembly. Dev Cell 18: 102-113.

Feng S, Cokus SJ, Zhang X, Chen PY, Bostick M, Goll MG, Hetzel J, Jain J, Strauss SH, Halpern ME, et al. 2010. Conservation and divergence of methylation patterning in plants and animals. Proc Natl Acad Sci 107: 8689-8694.

Garcia BA, Hake SB, Diaz RL, Kauer M, Morris SA, Recht J, Shabanowitz J, Mishra N, Strahl BD, Allis CD, et al. 2007. Organismal differences in post-translational modifications in histones $\mathrm{H} 3$ and H4. J Biol Chem 282: $7641-7655$.

Grewal SI, Klar AJ. 1997. A recombinationally repressed region between mat2 and mat3 loci shares homology to centromeric repeats and regulates directionality of mating-type switching in fission yeast. Genetics 146: $1221-1238$.

Gullerova M, Proudfoot NJ. 2008. Cohesin complex promotes transcriptional termination between convergent genes in S. pombe. Cell 132: 983-995.

Halic M, Moazed D. 2010. Dicer-independent primal RNAs trigger RNAi and heterochromatin formation. Cell 140: 504-516.

Hall IM, Shankaranarayana GD, Noma K, Ayoub N, Cohen A, Grewal SI. 2002. Establishment and maintenance of a heterochromatin domain. Science 297: 2232-2237.

Hamilton A, Voinnet O, Chappell L, Baulcombe D. 2002. Two classes of short interfering RNA in RNA silencing. EMBO J 21: 4671-4679.

He XJ, Hsu YF, Zhu S, Wierzbicki AT, Pontes O, Pikaard CS, Liu HL, Wang CS, Jin H, Zhu JK. 2009. An effector of RNA-directed DNA methylation in Arabidopsis is an ARGONAUTE 4- and RNA-binding protein. Cell 137: 498-508.

Henderson IR, Jacobsen SE. 2007. Epigenetic inheritance in plants. Nature 447: 418-424.

Horn PJ, Bastie JN, Peterson CL. 2005. A Rik1-associated, cullindependent E3 ubiquitin ligase is essential for heterochromatin formation. Genes Dev 19: 1705-1714.
Huisinga KL, Elgin SC. 2009. Small RNA-directed heterochromatin formation in the context of development: What flies might learn from fission yeast. Biochim Biophys Acta 1789: 3-16.

Iida T, Kawaguchi R, Nakayama J. 2006. Conserved ribonuclease, Eri1, negatively regulates heterochromatin assembly in fission yeast. Curr Biol 16: 1459-1464.

Irvine DV, Zaratiegui M, Tolia NH, Goto DB, Chitwood DH, Vaughn MW, Joshua-Tor L, Martienssen RA. 2006. Argonaute slicing is required for heterochromatic silencing and spreading. Science 313: $1134-1137$.

Jenuwein T, Allis CD. 2001. Translating the histone code. Science 293: $1074-1080$.

Jia S, Kobayashi R, Grewal SI. 2005. Ubiquitin ligase component Cul4 associates with Clr4 histone methyltransferase to assemble heterochromatin. Nat Cell Biol 7: 1007-1013.

Jia S, Noma K, Grewal SI. 2004. RNAi-independent heterochromatin nucleation by the stress-activated ATF/CREB family proteins. Science 304: 1971-1976.

Johnson LM, Bostick M, Zhang X, Kraft E, Henderson I, Callis J, Jacobsen SE. 2007. The SRA methyl-cytosine-binding domain links DNA and histone methylation. Curr Biol 17: 379-384.

Johnson LM, Law JA, Khattar A, Henderson IR, Jacobsen SE. 2008. SRAdomain proteins required for DRM2-mediated de novo DNA methylation. PLoS Genet 4: e1000280.

Joshua-Tor L, Hannon GJ. 2010. Ancestral roles of small RNAs: An agocentric perspective. Cold Spring Harb Perspect Biol doi: 10.1101/ cshperspect.a003772.

Kato H, Goto DB, Martienssen RA, Urano T, Furukawa K, Murakami Y. 2005. RNA polymerase II is required for RNAi-dependent heterochromatin assembly. Science 309: 467-469.

Kelly WG, Aramayo R. 2007. Meiotic silencing and the epigenetics of sex. Chromosome Res 15: 633-651.

Kennedy S, Wang D, Ruvkun G. 2004. A conserved siRNA-degrading RNase negatively regulates RNA interference in C. elegans. Nature 427: 645-649.

Kim DH, Saetrom P, Snove O Jr, Rossi JJ. 2008. MicroRNA-directed transcriptional gene silencing in mammalian cells. Proc Natl Acad Sci 105: $16230-16235$.

Kloc A, Zaratiegui M, Nora E, Martienssen R. 2008. RNA interference guides histone modification during the $S$ phase of chromosomal replication. Curr Biol 18: 490-495.

Li F, Goto DB, Zaratiegui M, Tang X, Martienssen R, Cande WZ. 2005. Two novel proteins, dos1 and dos2, interact with rik1 to regulate heterochromatic RNA interference and histone modification. Curr Biol 15: $1448-1457$.

Li F, Huarte M, Zaratiegui M, Vaughn MW, Shi Y, Martienssen R, Cande WZ. 2008. Lid2 is required for coordinating H3K4 and H3K9 methylation of heterochromatin and euchromatin. Cell 135: 272-283.

Lipardi C, Paterson BM. 2009. Identification of an RNA-dependent RNA polymerase in Drosophila involved in RNAi and transposon suppression. Proc Natl Acad Sci 106: 15645-15650.

Lippman Z, Martienssen R. 2004. The role of RNA interference in heterochromatic silencing. Nature 431: 364-370.

Lippman Z, May B, Yordan C, Singer T, Martienssen R. 2003. Distinct mechanisms determine transposon inheritance and methylation via small interfering RNA and histone modification. PLoS Biol 1: E367.

Maida Y, Yasukawa M, Furuuchi M, Lassmann T, Possemato R, Okamoto N, Kasim V, Hayashizaki Y, Hahn WC, Masutomi K. 2009. An RNAdependent RNA polymerase formed by TERT and the RMRP RNA. Nature 461: 230-235.

Mandell JG, Bahler J, Volpe TA, Martienssen RA, Cech TR. 2005. Global expression changes resulting from loss of telomeric DNA in fission yeast. Genome Biol 6: pR1.

Matzke M, Kanno T, Daxinger L, Huettel B, Matzke AJ. 2009. RNAmediated chromatin-based silencing in plants. Curr Opin Cell Biol 21: $367-376$. 
May BP, Lippman ZB, Fang Y, Spector DL, Martienssen RA. 2005. Differential regulation of strand-specific transcripts from Arabidopsis centromeric satellite repeats. PLoS Genet 1: e79.

Mette MF, Aufsatz W, van der Winden J, Matzke MA, Matzke AJ. 2000. Transcriptional silencing and promoter methylation triggered by double-stranded RNA. EMBO J 19: 5194-5201.

Mochizuki K, Fine NA, Fujisawa T, Gorovsky MA. 2002. Analysis of a piwi-related gene implicates small RNAs in genome rearrangement in tetrahymena. Cell 110: 689-699.

Morris KV, Chan SW, Jacobsen SE, Looney DJ. 2004. Small interfering RNA-induced transcriptional gene silencing in human cells. Science 305: $1289-1292$.

Mosammaparast N, Shi Y. 2010. Reversal of histone methylation: Biochemical and molecular mechanisms of histone demethylases. Annu Rev Biochem 79: 155-179.

Motamedi MR, Verdel A, Colmenares SU, Gerber SA, Gygi SP, Moazed D. 2004. Two RNAi complexes, RITS and RDRC, physically interact and localize to noncoding centromeric RNAs. Cell 119: 789-802.

Murakami H, Goto DB, Toda T, Chen ES, Grewal SI, Martienssen RA, Yanagida M. 2007. Ribonuclease activity of Dis 3 is required for mitotic progression and provides a possible link between heterochromatin and kinetochore function. PLOS ONE 2: e317.

Nicholson TB, Chen T. 2009. LSD1 demethylates histone and nonhistone proteins. Epigenetics 4: 129-132.

Nonomura K, Morohoshi A, Nakano M, Eiguchi M, Miyao A, Hirochika H, Kurata N. 2007. A germ cell specific gene of the ARGONAUTE family is essential for the progression of premeiotic mitosis and meiosis during sporogenesis in rice. Plant Cell 19: 2583-2594.

Olmedo-Monfil V, Duran-Figueroa N, Arteaga-Vazquez M, DemesaArevalo E, Autran D, Grimanelli D, Slotkin RK, Martienssen RA, Vielle-Calzada JP. 2010. Control of female gamete formation by a small RNA pathway in Arabidopsis. Nature 464: 628-632.

Partridge JF, Scott KS, Bannister AJ, Kouzarides T, Allshire RC. 2002. cisacting DNA from fission yeast centromeres mediates histone $\mathrm{H} 3$ methylation and recruitment of silencing factors and cohesin to an ectopic site. Curr Biol 12: 1652-1660.

Pikaard CS, Haag JR, Ream T, Wierzbicki AT. 2008. Roles of RNA polymerase IV in gene silencing. Trends Plant Sci 13: 390-397.

Popp C, Dean W, Feng S, Cokus SJ, Andrews S, Pellegrini M, Jacobsen SE, Reik W. 2010. Genome-wide erasure of DNA methylation in mouse primordial germ cells is affected by AID deficiency. Nature 463: $1101-1105$.

Qi Y, He X, Wang XJ, Kohany O, Jurka J, Hannon GJ. 2006. Distinct catalytic and non-catalytic roles of ARGONAUTE4 in RNA-directed DNA methylation. Nature 443: 1008-1012.

Reinhart BJ, Bartel DP. 2002. Small RNAs correspond to centromere heterochromatic repeats. Science 297: 1831.

Ruiz MT, Voinnet O, Baulcombe DC. 1998. Initiation and maintenance of virus-induced gene silencing. Plant Cell 10: 937-946.

Schalch T, Job G, Noffsinger VJ, Shanker S, Kuscu C, Joshua-Tor L, Partridge JF. 2009. High-affinity binding of Chp1 chromodomain to K9 methylated histone $\mathrm{H} 3$ is required to establish centromeric heterochromatin. Mol Cell 34: 36-46.
Shahbazian MD, Grunstein M. 2007. Functions of site-specific histone acetylation and deacetylation. Annu Rev Biochem 76: 75-100.

She X, Xu X, Fedotov A, Kelly WG, Maine EM. 2009. Regulation of heterochromatin assembly on unpaired chromosomes during Caenorhabditis elegans meiosis by components of a small RNA-mediated pathway. PLoS Genet 5: e1000624.

Sigova A, Rhind N, Zamore PD. 2004. A single Argonaute protein mediates both transcriptional and posttranscriptional silencing in Schizosaccharomyces pombe. Genes Dev 18: 2359-2367.

Simmer F, Buscaino A, Kos-Braun IC, Kagansky A, Boukaba A, Urano T, Kerr AR, Allshire RC. 2010. Hairpin RNA induces secondary small interfering RNA synthesis and silencing in trans in fission yeast. EMBO Rep 11: 112-118.

Slotkin RK, Vaughn M, Borges F, Tanurdzic M, Becker JD, Feijo JA, Martienssen RA. 2009. Epigenetic reprogramming and small RNA silencing of transposable elements in pollen. Cell 136: 461-472.

Takahashi K, Murakami S, Chikashige Y, Niwa O, Yanagida M. 1991. A large number of tRNA genes are symmetrically located in fission yeast centromeres. J Mol Biol 218: 13-17.

Tamaru H, Selker EU. 2001. A histone H3 methyltransferase controls DNA methylation in Neurospora crassa. Nature 414: 277-283.

Taverna SD, Li H, Ruthenburg AJ, Allis CD, Patel DJ. 2007. How chromatin-binding modules interpret histone modifications: Lessons from professional pocket pickers. Nat Struct Mol Biol 14: 1025-1040.

Teixeira FK, Heredia F, Sarazin A, Roudier F, Boccara M, Ciaudo C, Cruaud C, Poulain J, Berdasco M, Fraga MF, et al. 2009. A role for RNAi in the selective correction of DNA methylation defects. Science 323: $1600-1604$.

Thomson T, Lin H. 2009. The biogenesis and function of PIWI proteins and piRNAs: Progress and prospect. Annu Rev Cell Dev Biol 25: 355-376.

Vaucheret H, Beclin C, Fagard M. 2001. Post-transcriptional gene silencing in plants. J Cell Sci 114: 3083-3091.

Verdel A, Jia S, Gerber S, Sugiyama T, Gygi S, Grewal SI, Moazed D. 2004. RNAi-mediated targeting of heterochromatin by the RITS complex. Science 303: 672-676.

Volpe TA, Kidner C, Hall IM, Teng G, Grewal SI, Martienssen RA. 2002. Regulation of heterochromatic silencing and histone H3 lysine- 9 methylation by RNAi. Science 297: 1833-1837.

Volpe T, Schramke V, Hamilton GL, White SA, Teng G, Martienssen RA, Allshire RC. 2003. RNA interference is required for normal centromere function in fission yeast. Chromosome Res 11: 137-146.

Wassenegger M, Heimes S, Riedel L, Sanger HL. 1994. RNA-directed de novo methylation of genomic sequences in plants. Cell 76: 567-576.

Wierzbicki AT, Ream TS, Haag JR, Pikaard CS. 2009. RNA polymerase V transcription guides ARGONAUTE4 to chromatin. Nat Genet 41: 630-634.

Yamada T, Fischle W, Sugiyama T, Allis CD, Grewal SI. 2005. The nucleation and maintenance of heterochromatin by a histone deacetylase in fission yeast. Mol Cell 20: 173-185.

Zhang K, Mosch K, Fischle W, Grewal SI. 2008. Roles of the Clr4 methyltransferase complex in nucleation, spreading and maintenance of heterochromatin. Nat Struct Mol Biol 15: 381-388. 


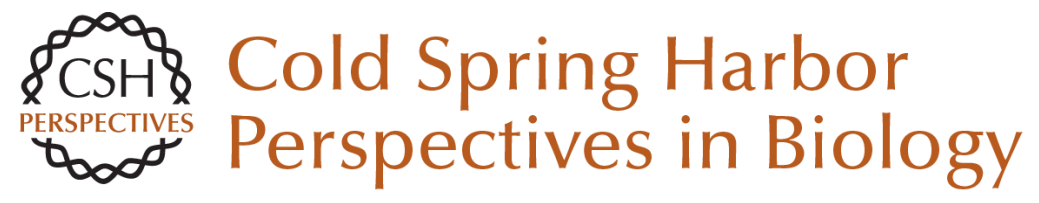

\section{RNA Interference and Heterochromatin Assembly}

Tom Volpe and Robert A. Martienssen

Cold Spring Harb Perspect Biol 2011; doi: 10.1101/cshperspect.a003731 originally published online January 19, 2011

\section{Subject Collection RNA Worlds}

Alternate RNA Structures

Marie Teng-Pei Wu and Victoria D'Souza

Approaches for Understanding the Mechanisms

of Long Noncoding RNA Regulation of Gene

Expression

Patrick McDonel and Mitchell Guttman

Principles and Practices of Hybridization Capture

Experiments to Study Long Noncoding RNAs That

Act on Chromatin

Matthew D. Simon and Martin Machyna

Linking RNA Sequence, Structure, and Function

on Massively Parallel High-Throughput

Sequencers

Sarah K. Denny and William J. Greenleaf

Extensions, Extra Factors, and Extreme

Complexity: Ribosomal Structures Provide

Insights into Eukaryotic Translation

Melanie Weisser and Nenad Ban

Nascent RNA and the Coordination of Splicing with Transcription

Karla M. Neugebauer

Combining Mass Spectrometry (MS) and Nuclear

Magnetic Resonance (NMR) Spectroscopy for Integrative Structural Biology of Protein-RNA

Complexes

Alexander Leitner, Georg Dorn and Frédéric H.-T. Allain
Structural Biology of Telomerase

Yaqiang Wang, Lukas Susac and Juli Feigon

Structural Insights into Nuclear pre-mRNA

Splicing in Higher Eukaryotes

Berthold Kastner, Cindy L. Will, Holger Stark, et al.

What Are 3' UTRs Doing?

Christine Mayr

\section{Single-Molecule Analysis of Reverse}

Transcriptase Enzymes

Linnea I. Jansson and Michael D. Stone

\section{CRISPR Tools for Systematic Studies of RNA}

Regulation

Jesse Engreitz, Omar Abudayyeh, Jonathan Gootenberg, et al.

Relating Structure and Dynamics in RNA Biology Kevin P. Larsen, Junhong Choi, Arjun Prabhakar, et al.

Beyond DNA and RNA: The Expanding Toolbox of

Synthetic Genetics Alexander I. Taylor, Gillian Houlihan and Philipp Holliger

For additional articles in this collection, see http://cshperspectives.cshlp.org/cgi/collection/

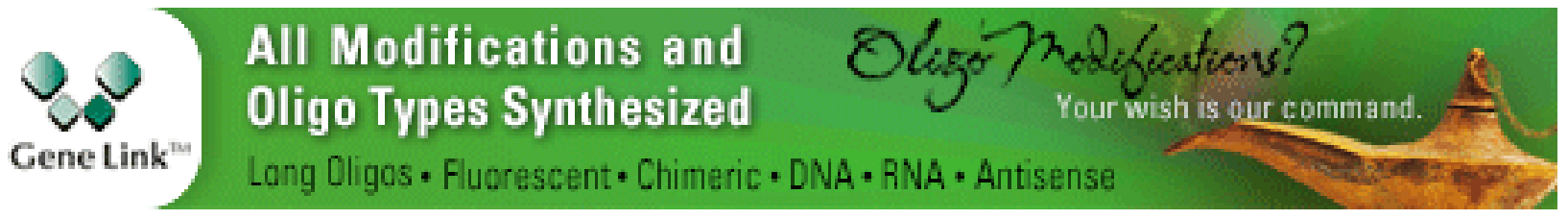

Copyright (C 2011 Cold Spring Harbor Laboratory Press; all rights reserved 
Discovering and Mapping the Modified Nucleotides That Comprise the Epitranscriptome of mRNA

Bastian Linder and Samie R. Jaffrey
Structural Basis of Nuclear pre-mRNA Splicing:

\section{Lessons from Yeast}

Clemens Plaschka, Andrew J. Newman and Kiyoshi Nagai

For additional articles in this collection, see http://cshperspectives.cshlp.org/cgi/collection/

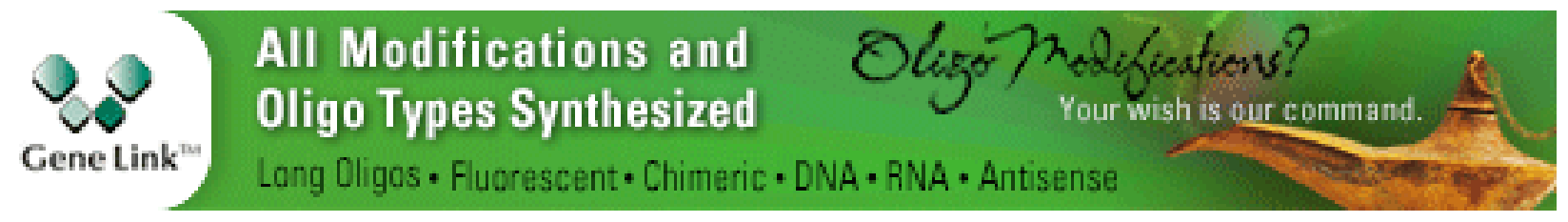

Copyright (C) 2011 Cold Spring Harbor Laboratory Press; all rights reserved 